\section{Leksikon dalamTradisi Sib Mimnyen (Cacing Laut/Nyale) di Kabupaten Halmahera Tengah}

\author{
Ashryani Sitinur M. Kamal \\ Hayatul Cholsy* \\ Linguistics Master Program, \\ Universitas Gadjah Mada \\ cholsy-h@ugm.ac.id
}

\begin{abstract}
This research was conducted to explore lexicon naming used in sib mimnyen tradition and the relationship with social values, community beliefs, and social activities. Data were collected using documentation techniques obtained from portraits of daily life and interviews with local communities. The research sample was randomly selected using random sampling technique. The results of this study found that the naming of nyale (marine worms) is influenced by several aspects such as language relation (Patani language in North Maluku - Thai Pattani language in Thailand), and the way of proccessing the worm, cognates vocabulary spesifically the sounds, and marine worm habitat. Furthermore, there were also non-language factors that supported determinism of sib mimnyen tradition consist of geographical location and social activities.
\end{abstract}

Keywords: lexicon; cultural determination; tradition; marine worms

\title{
ABSTRAK
}

Penelitian ini dilakukan dengan tujuan untuk menelisik penamaan leksikon yang digunakan dalam tradisi sib mimnyen dan hubungannya dengan nilai-nilai sosial, kepercayaan masyarakat, dan aktifitas sosial. Data dikumpulkan dengan menggunakan teknik dokumentasi yang diperoleh dari potret kehidupan sehari-hari dan wawancara terhadap masyarakat setempat. Sampel penelitian ini dipilih secara acak menggunakan teknik pengambilan sampel purposif. Hasil penelitian ini ditemukan penamaan nyale (cacing laut) dipengaruhi oleh beberapa aspek seperti hubungan kata antarbahasa (bahasa Patani Maluku Utara - bahasa Pattani Thailand), antarproses pengolahan, antarbunyi kosakata yang serupa (cognates vocabulary), dan habitat cacing laut. Selain itu, ditemukan juga faktor non bahasa yang menopang detrminasi budaya dalam tradisi sib mimnyen diantaranya letak geografis dan aktivitas sosial masyarakat.

Kata Kunci: leksikon; determinasi budaya; nyale

\section{PENDAHULUAN}

Setiap daerah memiliki budaya yang berbeda dengan daerah lainnya. Namun ada beberapa daerah yang memiliki kesamaan karakter budaya dengan budaya di daerah lain. Hal ini disebut dengan budaya serumpun atau daerah yang masih memiliki hubungan kekerabatan. Sebagaimana yang terjadi di Kabupaten Halmahera Tengah yang terletak di Provinsi Maluku Utara juga memiliki beberapa kesamaan karakter budaya dengan daerah-daerah timur Indonesia. Terdapat beberapa bagian atau bentuk dari budaya yg serupa dengan budaya lainnya yang sudah dibentuk oleh budaya itu sendiri dan bukan karena dipengaruhi oleh budaya tersebut. Sehingga budaya inilah yang membentuk perilaku komunikasi antar pelaku budaya yaitu encoder dan decoder (Mulyana dan Rakhmat 2006: 20-21). Dalam teori model komunikasi antarbudaya ini dipercaya bahwa komunikasi antarbudaya yang memiliki bentuk serupa jika berada dalam satu lingkaran yang sama maka dapat mempengaruhi perilaku komunikasi antarbudaya. Salah satu contoh dari bentuk budaya yang serupa tersebut adalah adanya kesamaan tradisi-tradisi adat tertentu yang dilaksanakan di pesisir pantai berkarang yakni yang dikenal dengan sebutan sib mimnyen (cacing laut).

Tradisi sib mimnyen ini memiliki beberapa kesamaan bentuk budaya dengan budaya serumpun lainnya di wilayah timur Indonesia. Namun, tradisi ini juga memiliki berbagai perbedaan baik dalam upacara adat penjemputan, proses pengolahan dan Kekhususan (istilah) yang dipakai oleh pelaku budaya tersebut. Hal tersebut juga terjadi dalam tradisi sib mimnyen, masyarakat di Kabupaten

$[1-12]$

Kamal, Ashryani Sitinur M. \& Hayatul Cholsy. 2021. Leksikon dalamTradisi Sib Mimnyen (Cacing Laut/Nyale) di Kabupaten Halmahera Tengah. Deskripsi Bahasa Vol.4(1) 2021, pp. 1 12. https://jurnal.ugm.ac.id/v3/db 
Halmahera Tengah meyakini adanya nilai-nilai moral dalam proses upacara adat penjemputan mimnyen, juga mempertahankan nilai-nilai tersebut sebagai bagian dari wujud budaya yang diyakini secara turun-temurun. Nilai yang dipertahankan tersebut kemudian dijadikan sebagai sebuah tradisi yang dikenal dengan sebutan tradisi sib mimnyen.

Di satu sisi, budaya dibentuk oleh masyarakat berdasarkan pola pikir, kegiatan sosial, kebiasaan sehari-hari, serta aktifitas yang dipengaruhi oleh hal-hal di sekitarnya. Pola pikir, perilaku, kebiasaan adalah sistem nilai yang membentuk istilah-istilah yang dibahasakan (Masinambow 1976: 6-7). Koentjaraningrat (Koentjaraningrat 2005: 75) berpendapat bahwa bahasa sebagai wujud budaya yang memiliki sistem, budaya dibentuk dari aktifitas manusia yang berpola, gagasan- gagasan, sistem tingkah laku, aktifitas masyarakat yang menghasilkan sesuatu secara fisik (artefak). Budaya itu terbentuk oleh kebiasaan masyarakat yang secara sengaja dan sadar. Sementara bahasa yang terdapat dalam tradisi itu dibentuk sebagai bagian dari budaya (Retnowati dan Manan 2014: 73-6). Penentuan atau penetapan satu tradisi atau budaya yang diyakini oleh masyarakat berdasarkan situasi juga disebut dengan determinasi budaya. M. J. Herskovits (1951) berpandangan dalam bukunya Man and His Works bahwa segala sesuatu yang terdapat dalam masyarakat ditentukan oleh kebudayaan yang dimiliki oleh masyarakat itu sendiri, istilah untuk pendapat ini dikenal dengan cultural- determinism (determinasi budaya).

Di sisi lainnya, fenomena dan situasi yang terjadi secara alamiah dalam suatu masyarakat terhadap suatu objek yang dapat dinilai dan dapat berpengaruh tersebut bersifat determinatif (Moleong 2007: 6). Sejalan dengan ini, determinasi budaya dalam aspek bahasa sebagai sistem budaya juga merupakan bagian dari warisan budaya salah satunya budaya gotong royong yang dikenal dengan istilah mapolus di minahasa dan huyula di daerah gorontalo (Sarajar, Rumajit, dan Walukow 1996: 76-77; Wujud, arti dan fungsi puncak-puncak kebudayaan lama dan asli 1996: 44).

Beberapa pandangan di atas memandang kebudayaan yang ada pada pelaku budaya tersebut terbentuk karena adanya sesuatu yang lain di luar budaya yang diyakini dan dibiasakan sehingga membentuk suatu tradisi. Sementara bahasa yang ada dalam budaya tersebut sebagai bagian dari wujud budaya yang bersifat turun-temurun atau dengan kata lain dari satu generasi ke generasi yang lain. Selain itu, dalam memaknai leksikon yang terdapat dalam sebuah tradisi, maka perlu dipahami hakikat bahasa, yakni 12 butir bahasa yang disarikan oleh Aslinda (2014: 1) yang di antaranya tentang bahasa sebagai wujud bunyi, bahasa bersifat produktif, dinamis, dan bervariasi. Hal ini menunjukkan bahwa bahwa itu relatif, yakni memiki keindahannya sendiri yang dapat dilihat dari simbol, lambang, fonem, dan bentuk kata (Wijana 2016: 81). Dengan demikian, bahasa Patani khususnya yang digunakan dalam tradisi sib mimnyen tentu dilatarbelakangi oleh aspek lain yang menjadikan leksikon dalam tradisi ini sedikit berbeda dengan leksikon lainnya yang digunakan dalam kehidupan seharihari.

Aspek-aspek yang melatarbelakangi pembentukan leksikon atau dikenal dengan determinasi budaya ini perlu diselisik lebih dalam guna mengungkapkan kekhasan dalam tradisi tersebut. Salah satunya yakni dengan mengkaji kosakata serumpun (cognate vocabulary) dengan lingkungan sekitar benda termasuk bahasa yang serumpun (Meyer 2009: 25-7). Selain itu juga dapat dilihat dari aspek-aspek non bahasa lainnya yang ditemukan dalam kehidupan sehari-hari masyarakat. Sib mimnyen sebagai tradisi yang diyakini masyarakat sejak ribuan tahun silam ini belum ada relevansi penelitian sebelumnya, khususnya pada aspek peristilahan yang ada dalam determinasi budaya. Sehingga data yang diperoleh sangat terbatas dan bersifat faktual.

Penelitian ini mengacu pada beberapa penelitian sebelumnya seperti yang telah diteliti oleh (Rajeg 2020) yang menganalisis koleksem khas berganda (MDCA) unntuk perbedaan dan kemiripan semantis di antara sinonim "kebahagiaan" bahasa Indonesia. Selain itu, penelitian kondisi sosial budaya yang mempengaruhi keberadaan bahasa juga dilakukan oleh (Pratiwi, Arka, dan Shiohara 2020). Penelitian tentang leksikon dan variabel-variabel penentu pembentukan leksikon juga diteliti oleh beberapa peneliti bahasa seperti (Dong, Mihalcea, dan Radev 2020), (María Mora dkk. 2020), (Viegas dkk. 2020), (Siew, Yi, dan Lee 2021), (Sakketou dan Ampazis 2020), (Preez dkk. 2020), (Vashishtha dan Susan 2019), (Khamekhem, Kessentini, dan Kanoun 2019), (Zora, Riad, dan Ylinen 2019), (Pelsmaeker dkk. 2019), (Wulff dkk. 2019), (Wahyuni dan Budi 2018), (Lavertu dan Altman 2019), (Touahri dan Mazroui 2019), (Ghiassi dan Lee 2018), (M Mora dkk. 2019), (Lupea dan Briciu 2019),(Aslan, Gunal, dan Dincer 2018), (Razavi 2018), (Ong dkk. 2019) telah mengekspolarasi leksikon 
berdasarkan ranah, aktivitas sosial, leksikon dalam komunitas, suku, daan kelompok tertentu. Namun dari sekian penelitian di atas, peneliti belum menemukan adanya tulisan berkaitan dengan faktor-faktor yang melatarbelakangi munculnya sebuah leksikon dalam tradisi tertentu? Dengan demikian, penelitian ini menjadi sangat menarik untuk dieksplorasi guna menelusuri apa saja aspek yang melatarbelakangi terbentuknya tradisi sib mimnyen dan leksikon khas yang ditemukan dalam tradisi tersebut.

Untuk menjawab pertanyan penelitian sebelumnya, maka peneliti menggunakan metode kualitatif yakni penelitian yang lebih menekankan pada segi kualitas secara alamiah yang melekat pada pengertian, konsep, ciri, nilai dan juga tidak menekankan pada angka statistik, perhitungan dan persentase. Creswell (2014) dan Kaelan (2012: 4-6) juga mendesain sebuah model penelitian etnografi yakni penelitian yang memfokuskan pada gambaran dalam menginterpretasikan suatu budaya dan kelompok sosial. Sehingga penelitian tentang sib mimnyen ini akan sangat tepat untuk diteliti menggunakan metode penelitian kualitatif dengan model etnografi kualitatif. Dalam penelitian ini, sampel yang digunakan adalah penutur asli masyarakat Patani. Teknik Pengumpulan data yang digunakan yakni teknik Random Sampling atau sering disebut dengan propability sampling. Random sampling adalah teknik yang digunakan oleh peneliti dengan keyakinan bahwa sampel yang dipilih memiliki probabilitas yang sama untuk dapat dipilih secara acak, selain itu purposive sampling juga dapat digunakan peneliti jika peneliti ingin memilih beberapa sampel yang memberikan informasi sesuai dengan kebutuhan peneliti (Koentjoro 2012: 105-6; Kumar 2011: 189; Berg 2001). Data yang dikumpulkan menggunakan metode wawancara melalui telepon seluler dan dokumentasi melalui media sosial. Wawancara dilakukan peneliti untuk dapat mnginterpretasikan situasi dan fenomena yang terjadi dalam masyarakat yang tidak dapat ditemukan hanya dengan melakukan observasi (Kaelan 2012: 110-11; Creswell 2014: 181). Selain itu, peneliti juga menggunakan teknik dokumentasi berupa gambar sebagai wujud keberadaan mimnyen dan sebagai data tambahan sebelum melakukan wawancara. Dengan demikian, teknik pengumpulan data melalui wawancara (Abdullah 2019; Hasim 2019; Ahmad 2019; Tahane 2019) dan dokumentasi dipilih oleh peneliti untuk menghasilkan data yang valid dan reliabel. Pola analisis data kemudian disusun menjadi data reduksi, data paparan, pemahaman, interpretasi, penafsiran dan pengambilan kesimpulan (Kaelan 2012: 13033; Berg 2001: 35-6)

\section{PEMBAHASAN}

Halmahera tengah dikenal dengan kabupaten yang memiliki banyak karang laut hidup (karang yang dapat tumbuh dan berkembang). Karang laut ini juga menjadi salah satu faktor pembentukan nyale (cacing laut) yang dikenal di daerah ini dengan sebutan mimnyen. Mimnyen merupakan hewan laut yang memiliki tekstur berupa butiran-butiran yang diyakini berasal dari bebatuan dan pasir pantai. Berikut data tentang determinasi Sib Mimnyen dan faktor-faktor non bahasa yang melatarbelakangi terbentuknya tradisi tersebut.

\section{Determinasi Geografi, Aktivitas Sosial Masyarakat dan Latar Belakang Pekerjaan}

Pola kehidupan sosial di Kabupaten Halmahera Tengah dapat ditinjau dari sudut pandang kegiatan sehari-hari (Koentjaraningrat dan Masinambow 1997: 71) dan dari letak geografis. Kegiatan sosial yang biasanya dilakukan masyarakat Patani yakni bercocok-tanam dan melaut. Kedua profesi ini kemudian dikembangkan dalam setiap aspek dalam kehidupan masyarakat, salah satunya dalam aspek sosial budaya masyarakat setempat. Masyarakat setempat kemudian memanfaatkan hasil panen yang diperoleh dengan pengemasan yang khas dan diikuti dengan beberapa upacara penyambutan yang dikenal dengan sib mimnyen. Kekhasan ini kemudian dilakukan turun-temurun hingga kini menjadi sebuah tradisi dalam kebudayaan masyarakat Patani di kabupaten Halmahera tengah.

Sementara itu, kegiatan sosial lainnya berdasarkan letak geografis dapat dilihat dari kegiatan seharihari lainnya yang dilakukan masyarakat untuk menopang hidup (selain bertani dan melaut). Masyarakat memanfaatkan karang hidup yang ada di sepanjang bibir pantai Halmahera tengah sebagai mata pencarian mereka. Karang-karang tersebut dipecahin menjadi satuan-satuan kecil seperti bebatuan, kerikil dan pasir. Kemudian pecahan-pecahan tersebut dijual untuk kelangsungan hidup mereka. Selain dijual pecahan-pecahan karang ini juga dijadikan sebagai bahan utama bangunan dan hiasan masyarakat setempat. Masyarakat setempat meyakini bahwa karang yang ada 
di daerah ini adalah jenis batu karang hidup sehingga dapat tumbuh kembali meskipun diambil terusmenerus. Hal ini dilakukan layaknya panen raya pohon kelapa dan cengkeh.

Selanjutnya proses pemecahan batu karang sebagai salah satu mata pencarian ini sudah dilakukan masyarakat setempat sejak dahulu kala. Mereka berlomba-lomba untuk memecahkan batu dari terbitnya fajar sampai terbenamnya matahari. Masyarakat setempat percaya bahwa mereka bisa hidup dengan memanfaatkan alam yang tumbuh bersama mereka. Kegiatan memecahkan batu ini kemudian mempertemukan mereka dengan salah satu biota laut yakni cacing laut atau dalam Bahasa Indonesia disebut nyale dan dikenal dalam bahasa Patani dengan sebutan mimnyen.

Mimnyen menjadi biota laut spesial untuk masyarakat setempat karena hanya muncul satu kali setahun di saat bulan purnama sempurna yakni pada perkiraan bulan April atau Mei. Selain dari kelangkaannya, mimnyen juga memiliki rasa yang lezat dan juga mengandung protein tinggi (Pamungkas 2015: 7). Karena kelebihan dan manfaatnya yang sangat banyak untuk dikonsumsi, mimnyen kemudian dijadikan sebagai bahan makanan yang paling ditunggu oleh masyarakat setempat. Mereka kemudian melakukan berbagai macam cara agar bisa mengambil banyak mimnyen untuk dapat dinikmati dalam kurun waktu panjang.

Cara-cara tersebut kemudian dikemas dengan sangat apik, mulai dari proses penjemputan layaknya upacara pada hari kemerdekaan. Penjemputan Mimnyen menggunakan tifa dan gong ${ }^{2}$. Masyarakat percaya bahwa dengan adanya penjemputan maka mimnyen akan keluar lebih banyak sehingga dapat diolah untuk dinikmati dalam jangka waktu yang lama. Proses penjemputan ini dilakukan turun-temurun oleh masyarakat setempat sehingga menjadi sebuah tradisi yang sampai sekarang dikenal dengan sebutan sib mimnyen. Sementara itu dalam proses pengolahannya, mimnyen memiliki kekhususan dalam penamaan hasil olahannya tersebut. Kekhususan istilah yang digunakan untuk setiap jenis olahan mimnyen dijelaskan pada pembahasan berikut.

\section{Determinasi Leksikon dalam Proses Pengolahan Mimnyen}

Berikut adalah leksikon yang digunakan dalam tradisi sib mimnyen. Leksikon yang digunakan sedikit berbeda dengan leksikon lain dalam bahasa Patani. Kosakata yang digunakan dalam tradisi sib mimnyen berbeda dengan kosakata yang digunakan dalam kehidupan sehari-hari dalam menyebutkan kondisi, keadaan, aktifitas, dan proses yang sama. Data leksikon disarikan sebagai berikut:

\section{a. Mimnyen [mimnen]}

Mimnyen dalam bahasa Patani memiliki arti mimnyen yang masih mentah atau dengan kata lain mimnyen yang belum diolah. Kata mimnyen memiliki asal kosakata serumpun (cognate vocabulary) dengan kata nyinyen (pasir) dalam bahasa Patani. Meyer (2009; 25-7) berasumsi bahwa kosakata serumpun adalah kata-kata yang memiliki kesamaan karakter, bunyi, dan makna dengan kata lainnya. Dapat dilihat dari karakter, bunyi dan makna dari kata mimnyen [mimnen] dan nyinyen [ninnen] keduanya memiliki bunyi yang serupa dan juga memiliki hubungan makna. Hal ini berlaku juga dalam penyebutan beberapa kata lainnya seperti bitbot (becek) sementara bitbot (hewan berbentuk kecil seperti kecoa dan ditemukan dalam tanah yang berair).

1 alat musik khas Indonesia timur yang terbuat dari bambu, isi bambu kemudian dibuang, sementara permukaan bambu ditutup dengan kulit rusa

2 alat musik tradisional sebagai pemberi tanda bahwa mimnyen sudah muncul dan siap untuk dijemput 


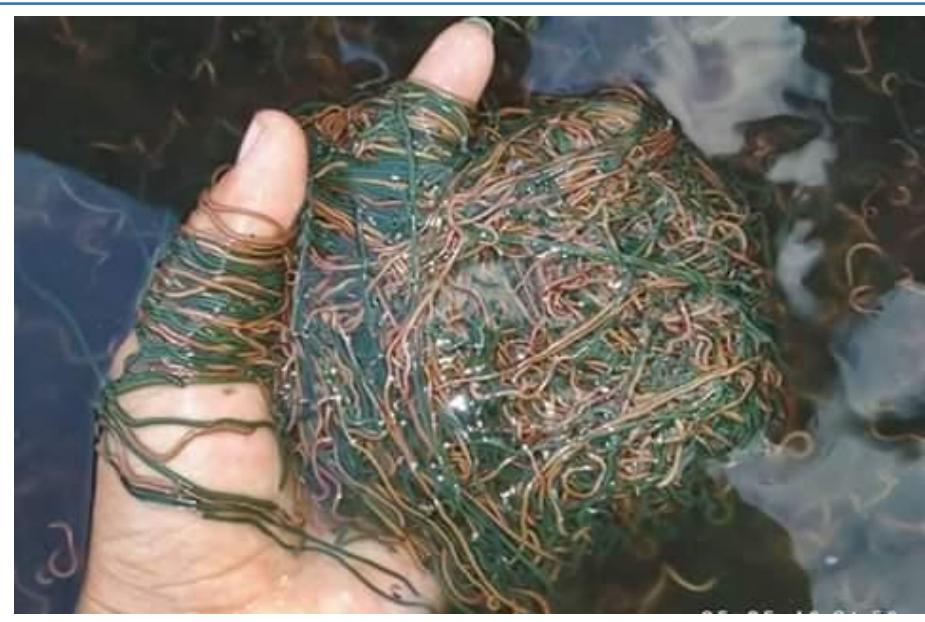

\section{Gambar 1. Mimnyen}

Dari sudut pandang hubungan makna, mimnyen adalah salah satu biota laut yang hanya ditemukan di pantai berkarang. Mimnyen juga diketahui berasal dari proses pengapungan pasir sebagai bagian dari hasil pemecahan karang-karang hidup oleh gelombang air laut pada saat purnama tinggi. Sementara nyinyen adalah pasir yang ada di pesisir pantai yang terbentuk dari pecahan-pecahan karang hidup dengan bantuan gelombang air laut. Di sisi lainnya, mimnyen dan nyinyen memiliki bunyi yang mirip ketika diujarkan. Sehingga dapat dikatakan bahwa kata mimnyen dan nyinyen adalah kosata serumpun.

Sementara itu dalam bahasa melayu Maluku Utara mimnyen dikenal dengan sebutan wawo. Kata wawo sendiri berasal dari bahasa Maluku (ambon). Pada awalnya istilah ini digunakan oleh masyarakat di Leitimor pulau Ambon (Pamungkas 2015: 2-3). sedangkan di Banda disebut Oele (Uli), di Hitu dan saparua di sebut Melaten, di Sumba (Provinsi Nusa tenggara Timur) oleh warga setempat menyebutnya Nyale (Horst 1904: 586), dan khusus di Patani (bagian dari Maluku Utara) dikenal dengan sebutan Mimnyen. Dalam Bahasa Indonesia, mimnyen resmi disebut dengan ejaan nyale. Sementara dalam bahasa latin mimnyen dikenal dengan sebutan Lysidice Oele, kata akhir dari nama latinnya ini diambil dari bahasa Banda dalam ekspedisi siboga yang dilakukan oleh Horst (1904).

\section{b. Wirwor [wirwor]}

Kata wirwor memiliki hubungan makna dengan weir mdib dalam bahasa Thai di Thailand yang berarti proses pengolahan (contoh kalimat Pra $m w l \bar{p} h l$ weir mdib yang memiliki makna cacing mentah yang diproses). Kesamaan istilah lainnya seperti pada kata deem dalam bahasa Thailand artinya minum dalam bahasa Patani dem artinya juga minum.

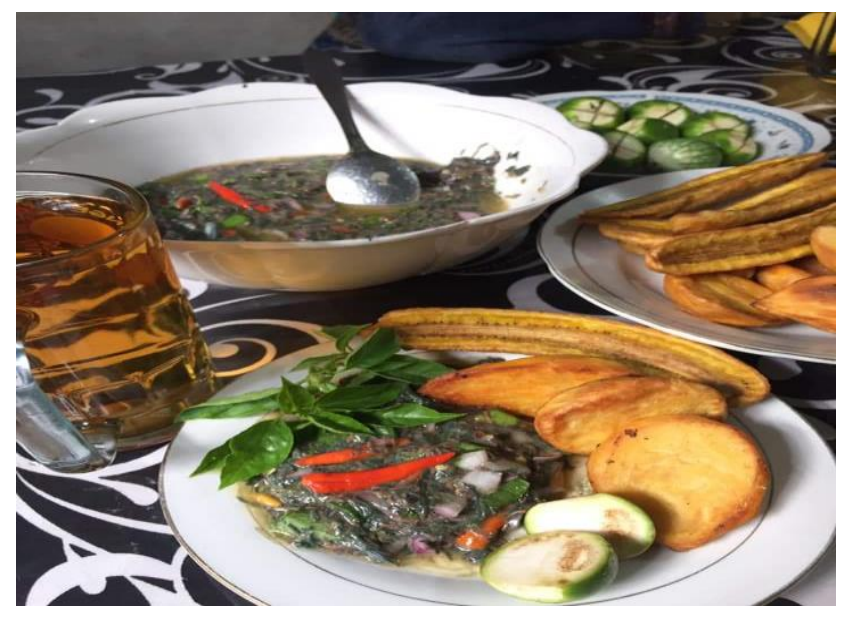

Gambar 2. Wirwor 
Hal ini menunjukkan bahwa adanya hubungan kekerabatan bahasa dalam Bahasa Patani dan Bahasa Thailand. Sementara itu, makna lainnya dari kata wirwor yang berkaitan dengan proses pengolahannya, yakni dicampur dengan berbagai rempah kemudian diaduk secara acak sampai benar-benar tercampur. Bunyi yang dihasilkan selama aktifitas mencampur terdengar mirip dengan kata wirwor. Sehingga dapat dikatakan bahwa berasal dari aktifitas kata itu sendiri. Sementara itu, Wirwor digunakan masyarakat khusus untuk menyebutkan mimnyen yang dapat langsung dimakan tanpa dimasak. Jadi, ketika mendengar kata wirwor tanpa kata mimnyen pun masyarakat sudah bisa mengetahui bahwa dimaksudkan tersebut adalah mimnyen wirwor. Dapat dikatakan bahwa, wirwor memang sebutan khusus untuk menggambarkan olahan mimnyen yang sebagaimana dimaksud.

Istilah wirwor dipakai untuk mimnyen yang masih segar dari laut kemudian disaring (konsetrat), lalu dicampur dengan fifo jinao (jeruk nipis bulat), bawa miccem (bawang merah), malkomoni wlu (daun kemangi), dan eget sinanga (minyak goreng). Mimnyen wirwor biasanya disajikan dengan camilan khusus seperti yof tu (sagu), tele sinanga (pisang goreng), kasbi sinanga (singkong goreng), kastelabet sinanga (ubi goreng). mimnyen wirwor biasanya bisa langsung disajikan tanpa dicampur dengan garam atau bumbu perasa lainnya, hal ini dilakukan karena masyarakat setempat percaya bahwa mimnyen sudah mengandung rasa asin yang tinggi karena berasal dari laut.

Di sisi lain, bumbu yang dimasukkan dalam Mimnyen wirwor dapat menguraikan komposisi dengan cepat sehingga bisa membantu melancarkan proses pencernaan. Selain itu karena mimnyen wirwor dapat terurai dengan cepat sehingga mimnyen wirwor hanya dapat dinikmati masyarakat dalam kurun waktu 1-2 hari saja.

Istilah wirwor dalam bahasa Patani memiliki arti dimakan tanpa dimasak terlebih dahulu. Sementara istilah lain untuk olahan yang dimakan sebelum dimasak (masih dalam keadaan mentah) disebut dengan gohu. Gohu digunakan untuk sajian makanan lain seperti in gohu (ikan yang dapat dimakan dalam keadaan mentah dan sudah dicampur dengan beberapa bumbu penyedap), tele gohu (pisang yang dapat dimakan dalam keadaan mentah dan belum diolah), sayor gohu (sayur yang dapat langsung dimakan tanpa dimasak).

\section{c. Kamasi [kamasi]}

Bunyi dari kata kamasi sendiri sangat dekat dengan bunyi kata kemas dalam bahasa Indonesia yang memiliki makna bersih, terbungkus, rapi dan kuat (PUEBI). Sehingga dapat disimpulkan bahwa istilah kata kamasi memiliki hubungan kosakata serumpun dengan kata kemas dalam bahasa Indonesia. Dapat disimpulkan bahwa, keduanya masih memiliki hubungan yang erat karena adanya kemiripan dalam proses dan tahapan dari kata tersebut.

Sebutan kamasi digunakan untuk mimnyen yang sudah ditiriskan menggunakan karung lalu digantung dan dibiarkan sampai benar-benar kering. Waktu yang dibutuhkan untuk mengeringkan mimnyen kamasi ini sekitar 1-2 hari. Istilah mimnyen kamasi ini digunakan masyarakat khusus untuk mimnyen yang ditiriskan dan tidak dapat digunakan untuk olahan lainnya seperti pada olahan ikan, sayur, buah dan lain-lain. Sehingga kata kamasi sudah menggambarkan mimnyen kamasi meskipun tidak disebutkan kata kamasi.

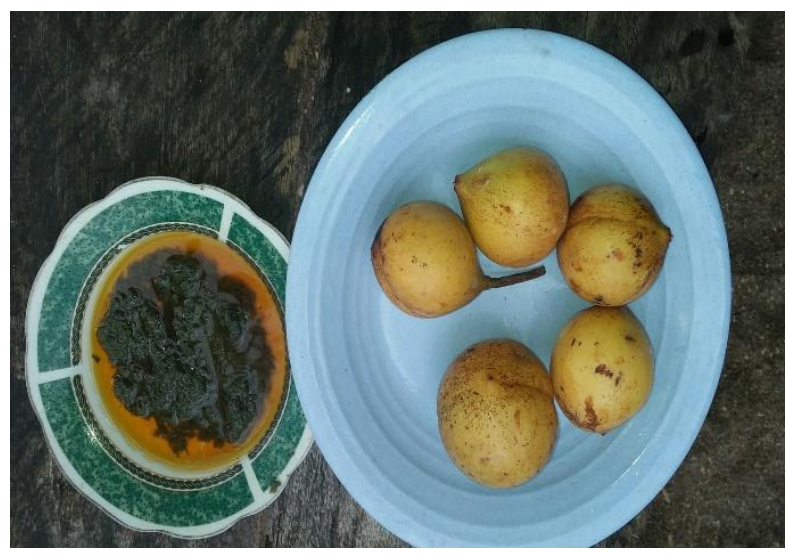

Gambar 3. Kamasi 
Berbeda dengan mimnyen wirwor yang tidak boleh campur dengan garam atau bumbu perasa lainnya, Mimnyen kamasi justru ciampur dengan garam yang cukup banyak. Masyarakat percaya bahwa mimnyen kamasi akan tahan lama (1-2 tahun) jika diawetkan dengan cara tersebut. Selain itu, mimnyen kamasi ini tidak boleh dicampur dengan air tawar karena nanti akan merusak kandungan mimnyen. Air tawar dianggap mampu merusak tekstur dan komposisi mimnyen sehingga mimnyen akan mudah mengalami pembusukan dan tidak dapat dikonsumsi dalam jangka waktu yang lama.

\section{d. Foto [fotoo]}

Istilah mimnyen fotoo dapat diartikan dengan mimnyen yang diasapi dengan arang tepat di bawah terik matahari. Hal ini kemudian membuat hubungan makna antara kata fotoo dengan terik matahari semakit jelas. Foto dalam PUEBI dijelaskan memiliki arti pantulan. Pantulan memiliki hubungan erat dengan cahaya sebagaimana yang terdapat dalam kata fotosintesis yang memiliki arti pemanfaatan cahaya matahari. Sehingga data disimpulkan bahwa kata fotoo memiliki hubungan erat dengan proses pembuatannya yakni pemanfaatan cahaya matahari.

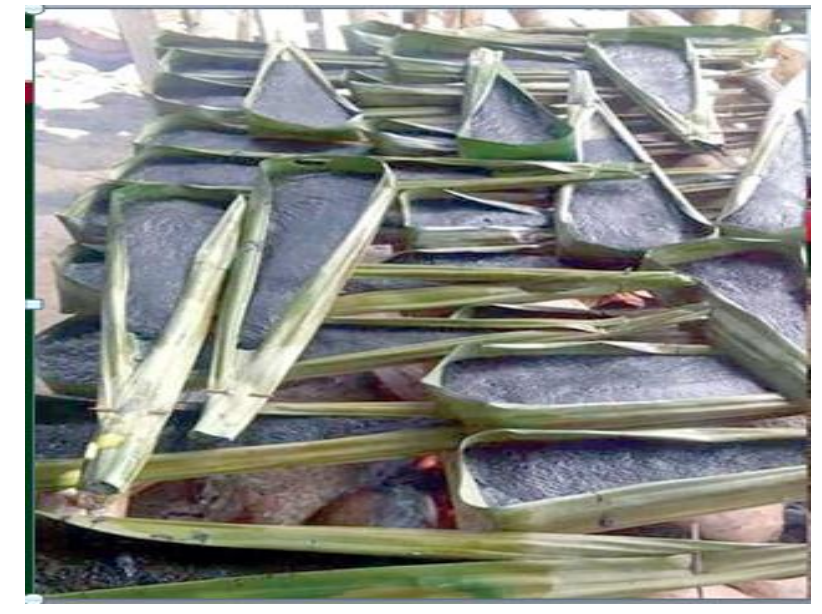

Gambar 4. Fotoo

Istilah mimnyen fotoo dapat diartikan dengan mimnyen yang diasapi dengan arang. Proses pembuatan mimnyen fotoo ini dilakukan masyarakat agar mereka dapat menikmati rasa yang berbeda dari mimnyen. Berbeda dengan tahapan sebelumnya, dalam pembuatan mimnyen fotoo, mimnyen tidak dicampur dengan garam, cukup dimasukkan ke dalam yofi wlu (daun sagu) yang sudah dibentuk. Pastikan bahwa yofi wlu yang digunakan sudah dibersihkan dan tidak berlubang sehingga mimnyen akan utuh sampai matang. Mimnyen yang sudah dimasukkan dalam yofi wlu kemudian diletakkan di atas raf (sebutan untuk kayu bertingkat yang biasa digunakan msyarakat untuk melakukan pengasapan makanan). Di bawah raf sudah disediakan arang yang siap digunakan untuk mengasapi mimnyen sampai benar-benar matang (kurang kebih 2-3 jam). Mimnyen fotoo biasanya dapat bertahan dan dikonsumsi kurang lebih 3-4 bulan. Hal ini disebabkan karena zat-zat yang terkandung dalam setelah adanya proses pengasapan mampu mengawetkan kandungan dan komposisi mimnyen fotoo.

Sementara itu, istilah untuk mimnyen fotoo digunakan masyarakat setempat khusus untuk penyebutan mimnyen yang diasapi di bawah terik matahari. Berbeda dengan makanan lainnya yang juga diasapi, seperti ikan asap dalam bahasa Patani disebut in fufu (ikan fufu), begitu juga dengan proses pengasapan bahan makanan lainnya, yang digunakan adalah istilah fufu. Hal ini menunjukkan bahwa ada keistimewaan yang dimiliki mimnyen. Sehingga untuk penyebutan kata fotoo sudah pasti yang dimaksud adalah mimnyen diasapi bukan ikan yang diasap, sayur asap, dan apalagi foto (mengambil gambar) dan makna lainnnya.

\section{e. Garoo [garoo]}

Bunyi kata garoo bahasa Patani memiliki hubungan erat dengan bunyi kata [garu] bahasa Indonesia. Dalam bahasa indoensia garu mengumpulkam, daun kering, potongan, serpihan denagn alat yang berbentuk seperti sisir besi. Proses pembuatan mimnyen garu ini menggunakan alat yang sama 
seperti penggaruk. Selain itu fungsinya juga sama yakni diolah dengan cara dikumpulkan lalu diseratkan dalam wajan sampaimengering.

Selain itu, Mimnyen garoo memiliki makna abon mimnyen atau dapat diartikan dengan masakan yang diserat-seratkan sampai matang. Jika abon diserat-seratkan dengan campuran bumbu dan digoreng (PUEBI), maka berbeda dengan mimnyen garoo. Mimnyen garoo adalah sisa yang tidak habis dimakan dari mimnyen wirwor sebelumnya kemudian diseratkan di dalam wajan sampai kering agar dapat dinikmati lagi.

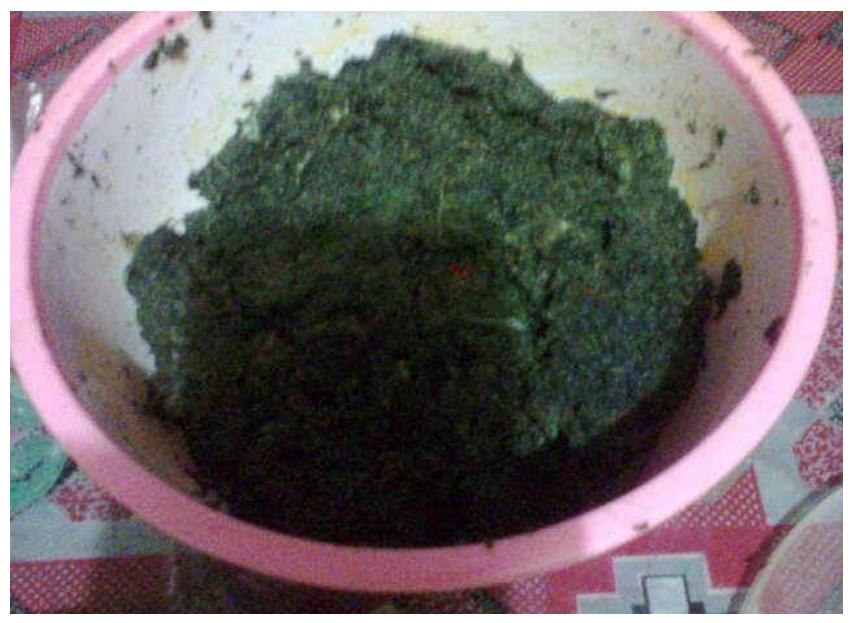

Gambar 5. Garoo

Biasanya mimnyen garoo dapat bertahan lebih lama dari mimnyen wirwor yakni 3-7 hari. Selain itu, harus dipastikan bahwa tidak ada air yang dicampurkan dalam olahan mimnyen garoo sehingga dapat mempertahankan keawetan mimnyen dalam jangka waktu yang lebih lama. Alat yang digunakan dalam proses pembuatan mimnyen garoo adalah pag-pagi (sejenis spatula yang terbuat dari kayu atau batang pohon kelapa), tit (tungku atau batu keras yang dipasang sebagai bahan perapian), dan yai (kayu-kayu pilihan yang dapat bertahan lama selama proses pembuatan mimnyen garoo.

\section{Determinasi Upacara Penjemputan Mimnyen}

Di kabupaten Halmahera tengah, khususnya di Wilayah Patani terdapat 4 kecamatan yakni Patani Utara, Patani Barat, Patani Timur dan Patani Selatan. Dalam kegiatan penjemputan mimnyen, masyarakat percaya bahwa dengan melakukan beberapa prosesi adat, maka mimnyen akan lebih cepat bereproduksi sehingga dapat dinikmati oleh seluruh anggota masyarakat. Mimnyen biasanya hanya muncul di kecamatan Patani Utara. Sehingga 3 hari sebelum munculnya mimnyen, kabar gembira ini akan disebarkan ke desa-desa tetangga yakni desa dari kecataman Patani Timur, Patani Selatan dan Patani Barat untuk mempersiapkan berbagai macam persiapan penjemputan mimnyen. Hal-hal yang perlu diketahui dan dipersiapkan sebelum proses penjemputan mimyen berupa:

\section{a. Mengidentifikasi Durasi dan Waktu Munculnya Mimnyen.}

Kebiasaan menangkap mimnyen sudah dilakukan sejak turun temurun. Pada bulan April atau Mei saat purnama pasang tinggi. Mimnyen biasanya muncul pada pukul 05.15-07.00 WIT. Mimnyen muncul tepat setelah shalat subuh. Biasanya akan terdengar suara riuh sana sini, kebisingan ombak, dan suara lalu lalang. Mimnyen akan mulai muncul perlahan-lahan dari balik karang. Tepat pada pukul o6.0o adalah puncaknya mimnyen bermunculan di permukaan air laut. Sehingga permukaan air laut akan terlihat berwarna hijau kecoklatan karena dipengaruhi oleh warna mimnyen.

Mimnyen yang muncul di pantai Patani biasanya berwarna cokelat, hijau, merah dan kuning. Teksturnya yang licin dan mudah hancur meninggalkan kesan tersendiri selama proses penangkapan. Harus sangat berhati-hati namun juga harus cepat diambil sebelum matahari terbit semakin tinggi. Karena panasnya matahari akan merusak tekstur tubuh mimnyen. Mimnyen bisa hancur dan melebur menyatu dengan air laut dan/atau bisa hancur menjadi satuan-satuan kecil seperti pasir. Teksturnya yang licin membuat mimnyen mudah lengket di kulit, baju dan alat penangkapan lainnya. Meskipun mimnyen bisa berenang, penangkapan mimnyen menjadi jauh lebih mudah dibandingkan dengan menangkap ikan atau hewan laut lainnya. 
Durasi penangkapan mimnyen yang terbilang cukup singkat yakni hanya sekitar 1-2 jam membuat masyarakat lebih kreatif untuk menciptakan berbagai macam alat yang bisa membantu proses pengambilan mimnyen dengan jumlah banyak dan dalam kurun waktu yang cepat.

\section{b. Persiapan Tempat Tinggal di Pesisir Pantai.}

Mimnyen biasanya hanya akan muncul di wilayah berkarang yakni di kecamatan Patani utara. Sehingga masayarakat di kecamatan lainnya harus berlomba-lomba untuk datang mengunjungi desa-desa yang di Patani utara 2-3 hari sebelum hari H penjemputan mimnyen. waktu pengambilan mimnyen yang jatuh pada waktu subuh membuat masyarakat berlomba-lomba untuk datang lebih awal agar bisa menyaksikan proses munculnya mimnyen. Selain itu, dengan datang lebih awal masyarakat dapat mengambil mimnyen dengan jumlah yang lebih banyak.

Oleh karena itu, sejak zaman dulu sampai sekarang, biasanya masyarakat akan membangun rumahrumah susun yang terbuat dari niwi potno (batang pohon kelapa) untuk dijadikan tiang serta yofiw lu (daun sagu) yang sudah dikeringkan untuk dijadikan atap rumah. Rumah-rumah ini biasanya dibangun di pesisir pantai dan/atau di atas karangkering.

\section{c. Peralatan dalam Persiapan Upacara Penjemputan Mimnyen.}

Masyarakat setempat biasanya menyiapkan beberapa hal yang akan dilakukan sebelum dan selama proses penjemputan. Persiapan dalam upacara penjemputan tersebut yakni alat musik dan lagu. Alat musik yang biasa digunakan seperti tifa (sejenis gendang yang biasa digunakan sebagai alat musik tradisional khas Indonesia Timur) dan gong (penanda bahwa mimnyen sudah muncul dan masyarakat siap untuk turun ke air). Lagu yang biasanya dinyanyikan disebut dengan lala (kumpulan lirik yang menggambarkan sejarah dan keadaan masyarakat setempat). Masyarakat menyanyikan lagu-lagu ini sepanjang malam untuk menjemput mimnyen. Masyarakat percaya bahwa mimnyen akan lebih banyak muncul jika diberi stimulus berupa nyanyian-nyanyian. Nyanyian-nyanyian ini juga digunakan sebagai undangan lisan untuk memanggil mimnyen agar cepat bereproduksi dan muncul di permukaan.

\section{d. Peralatan yang akan digunakan dalam pengambilan mimnyen.}

Keunikan dan kekhasan yang dimiliki mimnyen begitu istimewa di mata masyarakat. Karena kandungan gizi yang sangat tinggi sehingga baik untuk dikonsumsi. Tak jarang masyarakat belromba-lombaa untuk mengambil dengan jumlah yang banyak. Mereka kemudian menciptakan beberapa alat penangkapan yang khusus digunakan untuk menangkap mimnyen. Alat yang digunakan seperti:

1) Sib-sib, kata ini memiliki makna harfiah menggendong, sementara kata sib-sib digunakan untuk penyebutan sebuah alat penangkap mimnyen yang terbuat dari sehelai kain panjang yang diikat paada bagian ujungnya membentuk kerucut dan olo $u$ (tali rotan) yang sudah dibentuk bundaran. Sehelai kain dan tali rotan ini kemudian dijahit menyambung dan membentuk alat penyaringan yang digunakan untuk menangkap mimnyen. Hal ini menunjukkan bahwa masyarakat memaknai kata sib sebagai alat yang digunakan untuk menangkap mimnyen dengan cara yang lembut, agar tekstur tubuh mimnyen tidak rusak/putus.

2) Pajeko, penyebutan ini diyakini masyarakat sebagai alat untuk alat penangkap mimnyen yang dapat terapung. Alat ini terbuat dari dua batang bambu dengan ukuran mulai dari 1-3 meter, 2 gabus yang digunakan sebagai pelampung agar pajeko tidak tenggelam, dan 1 helai jaring keramba (jarring yang dianyam dari tali dan pelepah pohon) dengan ukuran 2- 3 meter. Jaring kemudian dijahit sepanjang tubuh bambu, sementara gabus diikatkan pada ujung bambu agar tidak tenggelam, di sisi lain dari ujung bambu dipegang. Pajeko juga dikenal dengan jaring penangkap mimnyen tanpa menggunakan kapal atau mesin sebagaimana penangkapan ikan atau hewan laut pada umumnya.

\section{KESIMPULAN}

Dari data determinasi budaya yang ada di Kabupaten Halmahera Tengah, dapat dipahami bahwa terbentuknya istilah dalam tradisi sib mimnyen adalah karena adanya hubungan bunyi dan makna 
yang masih memiliki kekerabatan (cognates vocabulary), serta hubungannya dengan asal usul objek. Selain itu ada juga istilah yang dibentuk karena adanya bunyi yang dihasilkan selama adanya aktifitas dari kata tersebut (hal ini berhubungan dengan aktifitas sosial masyarakat), dan juga karena ada pengaruh bahasa lain. Di samping itu juga dapat dilihat faktor non bahasa seperti letak geografis, kebiasaan masyarakat, dan aktifitas keseharian memiliki pengaruh besar dalam determinasi budaya sib mimnyen. Sehingga dalam kasus ini, disimpulkan bahwa bahasa sebagai wujud dari budaya, sementara budaya terbentuk karena adanya determinasi.

\section{DAFTAR PUSTAKA}

Abdullah, H. H. 2019. Hubungan Bahasa Patani dengan Bahasa Thailand Diwawancara oleh Ashryani Sitinur M Kamal. Wawancara langsung.

Ahmad, F.H. 2019. Sejarah Penjemputan Sib Mimnyen Diwawancara oleh Ashryani Sitinur M Kamal. Wawancara langsung.

Aslan, Ozkan, Serkan Gunal, dan B Taner Dincer. 2018. "ScienceDirect A computational morphological lexicon for Turkish: TrLex." Lingua 206. Elsevier B.V.: 21-34. doi:10.1016/j.lingua.2018.01.003.

Aslinda, Leni Syafyahya. 2014. Pengantar sosiolinguistik. Cetakan ke-3. Bandung: Refika Editama.

Berg, Bruce L. 2001. Qualitative Research Methods for the Social Sciences. Boston: Allyn and Bacon.

Creswell, John W. 2014. Research Design Qualitative, Quantitative, and Mixed Methods Approaches. Los Angeles: SAGE.

Dong, MeiXing, Rada Mihalcea, dan Dragomir Radev. 2020. "Extending Sparse Text with Induced Domain-Specific Lexicons and Embeddings: A Case Study on Predicting Donations." Computer Speech \& Language 59 (Januari): 157-68. doi:10.1016/j.csl.2019.06.007.

Ghiassi, M, dan S Lee. 2018. "A domain transferable lexicon set for Twitter sentiment analysis using a supervised machine learning approach." Expert Systems With Applications 106. Elsevier Ltd: 197-216. doi:10.1016/j.eswa.2018.04.006.

Hasim, Y. 2019. Istilah yang Digunakan dalam Tradisi Sib MimnyenWawancara langsung.

Herskovits, Melville Jean. 1951. Man and His Works. New York: Knopf.

Kaelan. 2012. Metode Penelitian Kualitatif Interdisipliner : Bidang Sosial, Budaya, Filsafat, Seni, Agama dan Humaniora. Yogyakarta: Paradigma.

Khamekhem, Sana, Yousri Kessentini, dan Slim Kanoun. 2019. "Out of vocabulary word detection and recovery in Arabic handwritten text recognition" 93. Elsevier Ltd: 507-20. doi:10.1016/j.patcog.2019.05.003.

Koentjaraningrat. 2005. Pengantar antropologi. Jakarta: Rineka Cipta.

Koentjaraningrat, dan E. K. M Masinambow. 1997. Koentjaraningrat dan antropologi di Indonesia. Jakarta: Asosiasi Antropologi Indonesia bekerjasama dengan Yayasan Obor Indonesia.

Koentjoro. 2012. Metodologi penelitian kualitatif. Jakarta: Salemba Humanika.

Kumar, Ranjit. 2011. Research Methodology: A Step-by-Step Guide for Beginners. Los Angeles: SAGE.

Lavertu, Adam, dan Russ B Altman. 2019. "RedMed: Extending drug lexicons for social media applications." Journal of Biomedical Informatics 99 (October). Elsevier: 103307. doi:10.1016/j.jbi.2019.103307.

Lupea, Mihaiela, dan Anamaria Briciu. 2019. "Studying emotions in Romanian words using Formal Concept." Computer Speech \& Language 57. Elsevier Ltd: $128-45$. doi:10.1016/j.csl.2019.02.005.

Masinambow, E. K. M. 1976. "Konvergensi etnolinguistis di Halmahera Tengah: sebuah analisa pendahuluan." Disertasi, Jakarta: Fakultas Sastra, Universitas Indonesia.

Meyer, Charles F. 2009. Introducing English Linguistics. https://doi.org/10.1017/CBO9780511757822. 
Moleong, Lexy J. 2007. Metodologi penelitian kualitatif. Bandung: Remaja Rosdakarya.

Mora, M, B Giussani, E Pagliarini, dan C Chaya. 2019. "Improvement of an emotional lexicon for the evaluation of beers." Food Quality and Preference 71 (June 2018). Elsevier: 158-62. doi:10.1016/j.foodqual.2018.06.007.

Mora, María, Amanda Dupas de Matos, Virginia Fernández-Ruiz, Teresa Briz, dan Carolina Chaya. 2020. "Comparison of Methods to Develop an Emotional Lexicon of Wine: Conventional vs Rapid-Method Approach." Food Quality and Preference 83 (Juli): 103920. doi:10.1016/j.foodqual.2020.103920.

Mulyana, Deddy, dan Jalaluddin Rakhmat. 2006. Komunikasi antarbudaya: panduan berkomunikasi dengan orang-orang berbeda budaya. Jakarta, Indonesia: PT Remaja Rosdakarya.

Ong, Gabriel, Meredith Mckague, Brendan Weekes, dan David K Sewell. 2019. "Diffusing the bilingual lexicon : Task-based and lexical components of language switch costs." Cognitive Psychology 114 (February). Elsevier: 101225. doi:10.1016/j.cogpsych.2019.101225.

Pamungkas, Joko. 2015. "Species richness and macronutrient content of wawo worms (Polychaeta, Annelida) from Ambonese waters, Maluku, Indonesia." Biodiversity Data Journal, no. 3 (Februari): 1-8. doi:10.3897/BDJ.3.e4251.

Pelsmaeker, Sara De, Gil De Clercq, Xavier Gellynck, dan Joachim J Schouteten. 2019. "Development of a sensory wheel and lexicon for chocolate." Food Research International 116 (September 2018). Elsevier: 1183-91. doi:10.1016/j.foodres.2018.09.063.

Pratiwi, Desak Putu Eka, I. Wayan Arka, dan Asako Shiohara. 2020. "Socio-Cultural Dynamics And Ethnolinguistic Vitality Of Sembiran Balinese." Linguistik Indonesia 38 (2): 95-103. doi:10.26499/li.v38i2.174.

Preez, B V P, D De Beer, E I Moelich, M Muller, dan E Joubert. 2020. "Development of chemical-based reference standards for rooibos and honeybush aroma lexicons." Food Research International 127 (October 2019). Elsevier: 108734. doi:10.1016/j.foodres.2019.108734.

Rajeg, Gede Primahadi Wijaya. 2020. "Linguistik Korpus Kuantitatif Dan Kajian Semantik Leksikal Sinonim Emosi Bahasa Indonesia." Linguistik Indonesia 38 (2): 123-50. doi:10.26499/li.v38i2.155.

Razavi, Marzieh. 2018. "Towards weakly supervised acoustic subword unit discovery and lexicon development using hidden Markov models." Speech Communication 96 (March 2017). Elsevier: 168-83. doi:10.1016/j.specom.2017.11.011.

Retnowati, Endang, dan M. Azzam Manan, ed. 2014. Identifikasi bahasa \& kebudayaan etnik minoritas Kao. Cetakan pertama. Menteng, Jakarta: LIPI Press.

Sakketou, Flora, dan Nicholas Ampazis. 2020. "Knowledge-Based Systems A constrained optimization algorithm for learning GloVe embeddings with semantic lexicons ts." KnowledgeBased Systems 195. Elsevier B.V.: 105628. doi:10.1016/j.knosys.2020.105628.

Sarajar, Rumajit, dan Walukow. 1996. Persepsi tentang etos kerja kaitannya dengan nilai budaya masyarakat di daerah Sulawesi Utara. Manado: Departemen Pendidikan dan Kebudayaan Bagian proyek pengkajian dan Pembinaan Nilai-nilai Budaya Sulawesi Utara.

Siew, Cynthia S Q, Kwangoh Yi, dan Chang H Lee. 2021. "Syllable and letter similarity effects in Korean : Insights from the Korean Lexicon Project." Journal of Memory and Language 116 (December 2019). Elsevier: 104170. doi:10.1016/j.jml.2020.104170.

Tahane, M.K. 2019. Sejarah Tradisi Sib MimnyenWawancara langsung.

Touahri, Ibtissam, dan Azzeddine Mazroui. 2019. "Studying the effect of characteristic vector alteration on Arabic sentiment classification." Journal of King Saud University - Computer and Information Sciences, no. xxxx. The Authors. doi:10.1016/j.jksuci.2019.04.011. 
Vashishtha, Srishti, dan Seba Susan. 2019. "Fuzzy rule based unsupervised sentiment analysis from social media posts" 138. Elsevier Ltd. doi:10.1016/j.eswa.2019.112834.

Viegas, Felipe, Mário S Alvim, Sérgio Canuto, dan Thierson Rosa. 2020. "Exploiting semantic relationships for unsupervised expansion of sentiment lexicons." Information Systems 94. Elsevier Ltd.: 101606. doi:10.1016/j.is.2020.101606.

Wahyuni, Rinda, dan Indra Budi. 2018. "ScienceDirect ScienceDirect Combining Linguistic, Semantic and Lexicon Feature for Emoji Combining Linguistic, Semantic and Lexicon Feature for Emoji Classification in Twitter Dataset Classification in Twitter Dataset." Procedia Computer Science 135. Elsevier B.V.: 194-201. doi:10.1016/j.procs.2018.08.166.

Wijana, I. Dewa Putu. 2016. Sosiolinguistik: Kajian teori dan analisis. Cetakan ke-4. Yogyakarta: Pustaka Pelajar.

Wujud, arti dan fungsi puncak-puncak kebudayaan lama dan asli. 1996. Jakarta: Departemen Pendidikan dan Kebudayaan. http://36.89.24.67:82/layanan-jabar/opac/detail-opac?id=33874.

Wulff, Dirk U, Simon De Deyne, Michael N Jones, dan Rui Mata. 2019. "New Perspectives on the Aging Lexicon." Trends in Cognitive Sciences 23 (8). The Authors: 686-98. doi:10.1016/j.tics.2019.05.003.

Zora, Hatice, Tomas Riad, dan Sari Ylinen. 2019. "Prosodically controlled derivations in the mental lexicon." Journal of Neurolinguistics $52 \quad$ (June). Elsevier: 100856. doi:10.1016/j.jneuroling.2019.100856. 